\title{
Clinical Characteristics of Idiopathic Epidermoid and Dermoid Cysts of the Ear
}

\author{
Yesun Cho and Dong-Hee Lee \\ Department of Otolaryngology-Head and Neck Surgery, College of Medicine, The Catholic University of Korea, Seoul, Korea
}

Received February 10, 2017

Revised April 4, 2017

Accepted April 10, 2017

\author{
Address for correspondence \\ Dong-Hee Lee, MD, PhD \\ Department of Otolaryngology- \\ Head and Neck Surgery, \\ Uijeongbu St. Mary's Hospital, \\ College of Medicine, \\ The Catholic University of Korea, \\ 271 Cheonbo-ro, Uijeongbu 11765, \\ Korea \\ Tel $+82-31-820-3564$ \\ Fax $+82-31-847-0038$ \\ E-mail leedh0814@catholic.ac.kr
}

Background and Objectives: Epidermoid and dermoid cysts are benign cystic lesions, lined by ectodermal squamous epithelium. They are not common in the head and neck areas, which constitute $\sim 7 \%$ of all cases of epidermoid and dermoid cysts. The aim of this study was to investigate the clinical characteristics of epidermoid and dermoid cysts that developed around the ear. Subjects and Methods: The clinical records were retrospectively reviewed for patients confirmed histologically as idiopathic epidermoid and dermoid cysts of the ear from January 2011 to December 2015. Results: Total 15 cases consisted of 14 epidermoid cysts and only 1 dermoid cyst. There were 11 males and 4 females (mean age of $37.8 \pm 16.8$ years old). Right side was 7 cases and left was 8 . The cyst was located at the lobule in 4 cases, at the ear canal in 4 cases, at the preauricular area in 4 cases, and at the postauricular area in 3 cases. In cases of epidermoid cysts, there was no significant difference in age, sex, and size according to the location. Patients with cysts on helix were younger than others. Conclusions: This study demonstrated that most cutaneous cysts developing around the ear were epidermoid cysts and there was no site preference for occurrence of epidermoid cysts.

J Audiol Otol 2017;21(2):77-80

\section{Introduction}

Both epidermoid and dermoid cysts are subcutaneous cyst lined by a thin layer of ectodermal squamous epithelium but have different complexity. Epidermoid cysts have only a cheesy material composed of sebum and epithelial debris, which are made from squamous epithelium but dermoid cysts contain hair, sebaceous and sweat glands, and squamous epithelium. Acquired types of both arise from trapped pouches or nearnormal folds of ectoderm, which can be induced by traumatic implantation of the squamous epithelium or obstruction of the duct of a sebaceous gland (pilosebaceous follicle). Congenital epidermoid and dermoid cysts are usually developed because the surface ectoderm fails developmentally to separate from the neural tube [1-5].

Epidermoid and dermoid cysts can occur anywhere from

This is an Open Access article distributed under the terms of the Creative Commons Attribution Non-Commercial License (http://creativecommons.org/licenses/by-nc/4.0/) which permits unrestricted non-commercial use, distribution, and reproduction in any medium, provided the original work is properly cited. the skin covering a body and cases of head and neck regions constitute about $7 \%$ of all cases. Clinicians often have a diagnostic dilemma because there are more common cystic lesions in the head and neck regions. Clinically, epidermoid and dermoid cysts appear as smooth, round, doughy masses that may have a tiny surface opening. They are usually asymptomatic. However, when a cyst becomes infected, its lining may be ruptured, thick cheesy keratin squames within it can spill out into the surrounding soft tissue, and this can give rise to local tenderness and swelling clinically.

In this study, we investigated the characteristics of epidermoid/dermoid cyst of the ear and focus on the review of clinicopathologic features and biologic behavior. We also compared the differences according to the location of cyst.

\section{Subjects and Methods}

The clinical records were retrospectively reviewed for patients confirmed histologically as epidermoid and dermoid cysts of the ear from January 2011 to December 2015. Only 
cases of which epidermoid or dermoid cysts were confirmed histopathologically at one university-based, secondary referral hospital were enrolled into this study. Acquired cases in which cysts develop after ear piercing were excluded from this study.

This study protocol was approved by the Institutional Review Board (IRB No. UC16RISI0071). The informed consent for the clinical study was waived because of retrospective chart review.

We analyzed the clinical findings of the epidermoid/dermoid cysts, such as gender, age, clinical features (including size, detail location, symptom duration, pain/tenderness and trauma history), histopathologic diagnosis and recurrence. We compared the characteristics of epidermoid/dermoid cysts according to their location. The size of the cyst was determined based on real measurements taken from an excised specimen, taking the measurement of the long axis and of the short axis at right angles to the long axis and calculating the product of the two measurements.
Data were described using the mean \pm standard deviation. Statistical analysis was performed by using IBM-SPSS statistics software (version 22; IBM Corporation, New York, NY, USA). Kruskall Wallis test was used to analyze continuous variables according the location. Mann Whitney U-test was used to analyze continuous variables between two groups. Fisher's exact test was used to analyze categorical variables. $p$-values less than 0.05 were considered to be significant.

\section{Results}

Total 15 cases (11 males and 4 females) consisted of 14 epidermoid cysts and only 1 dermoid cyst (Table 1, Fig. 1). The mean age of patients was $37.8 \pm 16.8$ years old. The youngest patient was 5.2 years old girl and the oldest was 59.6 years old men. Right-sided cases were 7 cases and left were 8. Painless swelling was common symptoms and only 32.8 years old man with epidermoid cyst on his lobule complaint the pain.

Table 1. Summary of clinical features of 15 cases

\begin{tabular}{|c|c|c|c|c|c|c|c|c|}
\hline Patient no. & Sex & $\begin{array}{c}\text { Age } \\
\text { (years) }\end{array}$ & Side & $\begin{array}{l}\text { Size } \\
(\mathrm{mm})\end{array}$ & $\begin{array}{l}\text { Duration } \\
\text { of symptom }\end{array}$ & Operation & $\begin{array}{c}\text { Histopathologic } \\
\text { diagnosis }\end{array}$ & Recurrence \\
\hline 1 & Male & 36.5 & Left & $10 \times 6$ & Several years & Excision & Epidermoid cyst & No \\
\hline 2 & Female & 30.1 & Left & $25 \times 15$ & Several decades & Excision & Epidermoid cyst & No \\
\hline 3 & Male & 12.6 & Left & $20 \times 8$ & Several years & Excision & Epidermoid cyst & No \\
\hline 4 & Female & 5.2 & Left & $13 \times 10$ & 1 year & Excision \& FTSG & Dermoid cyst & No \\
\hline 5 & Male & 45.4 & Left & $13 \times 11$ & 1 year & Excision & Epidermoid cyst & No \\
\hline 6 & Male & 21.6 & Right & $15 \times 12$ & Unknown & Excision & Epidermoid cyst & No \\
\hline 7 & Male & 39.1 & Left & $13 \times 10$ & 3 years & Excision & Epidermoid cyst & No \\
\hline 8 & Female & 48.1 & Left & $10 \times 6$ & 3 years & Excision & Epidermoid cyst & No \\
\hline 9 & Male & 32.8 & Right & $14 \times 10$ & 4 months & Excision \& FTSG & Epidermoid cyst & Yes \\
\hline 10 & Male & 59.6 & Right & $5 \times 4$ & Several years & Excision & Epidermoid cyst & No \\
\hline 11 & Male & 57.5 & Left & $5 \times 3$ & 4 days & Excision & Epidermoid cyst & No \\
\hline 12 & Male & 22.5 & Right & $9 \times 8$ & 3 months & Excision & Epidermoid cyst & No \\
\hline 13 & Male & 52.3 & Right & $17 \times 12$ & 3 months & Excision & Epidermoid cyst & No \\
\hline 14 & Female & 49.6 & Right & $18 \times 14$ & Several months & Excision & Epidermoid cyst & No \\
\hline 15 & Male & 54.6 & Right & $15 \times 11$ & Several years & Excision & Epidermoid cyst & No \\
\hline
\end{tabular}

FTSG: full-thickness skin graft
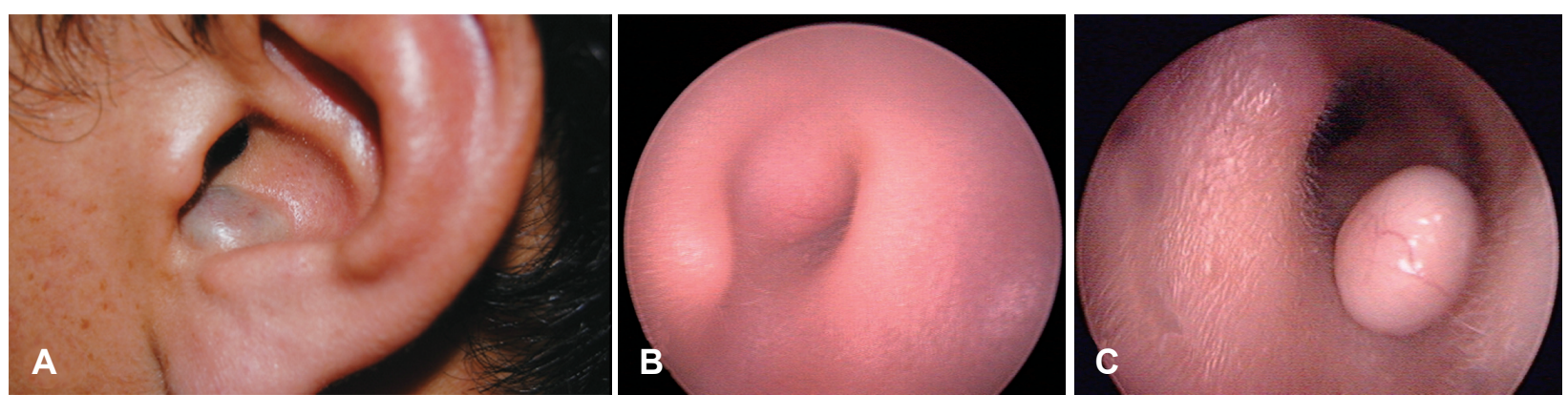

Fig. 1. Photos of cysts of ear canal. A: Patient number 1: a $10 \times 6 \mathrm{~mm}$-sized cyst was located in the cavum concha. B: Patient number 4: a $13 \times 10 \mathrm{~mm}$-sized cyst was located at anterosuperior portion of the cartilaginous ear canal. C: Patient number 12: a $9 \times 8 \mathrm{~mm}-\mathrm{sized}$ cyst was located on anterior wall of the cartilaginous ear canal. 
The mean sizes of long and short axes were respectively $13.5 \pm$ 5.4 and $9.3 \pm 3.5 \mathrm{~mm}$, and the product of long and short axes was $140.4 \pm 93.4 \mathrm{~mm}^{2}$. The cyst was located at the lobule in 4 cases, at the ear canal in 4 cases, at the preauricular area in 4 cases, and at the postauricular area in 3 cases (Fig. 2).

The mean period of follow-up was 1.3 months (follow-up range, 1-14 months). No surgical complications were reported during or after the excision, but one recurrence developed during the follow-up period. The cyst recurred about 1 year after the excision on 32.8 years old man with epidermoid cyst on his lobule, who was only patient with painful cyst at the presentation.

\section{Comparison according to the location of cysts (Table 2)}

Four clinical characteristics were compared according to the location; age, sex, size, and side. This study did not find out any significant difference according to the location (age, $p=0.329$; sex, $p=0.919$; size, $p=0.178$; side, $p=0.062$ ). Patients with cysts on helix were younger than others. There was a significant difference in age between cysts of the helix

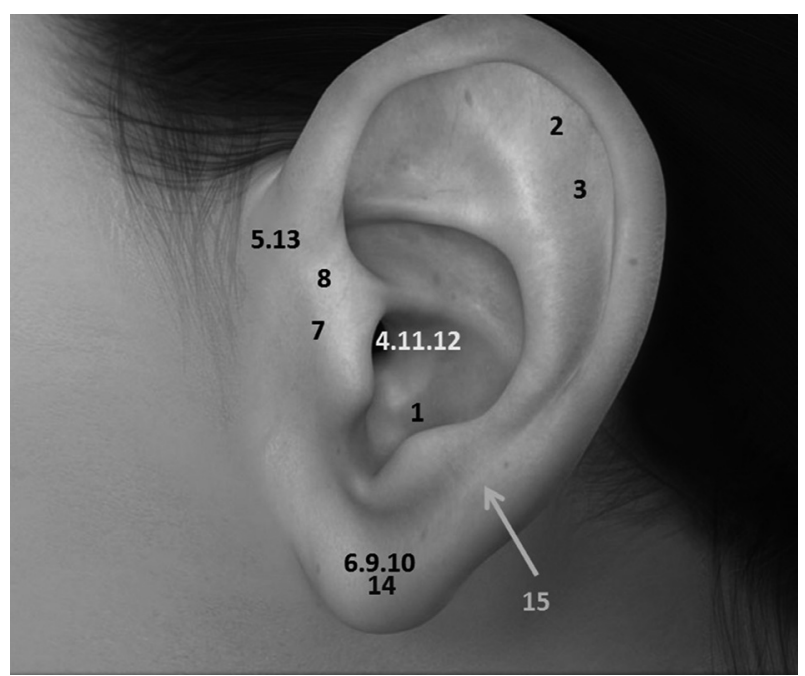

Fig. 2. Summary of detail locations of the lesion in 15 cases. The numbers of this figure correspond with the patient number of Table 1. Number 4, 11, and 12 were cysts in the cartilaginous ear canal and number 1 was a cyst in the cavum concha. Number 2, 3, and 14 were cysts on posterior side of auricle. Number 15 was a cyst along postauricular sulcus.

Table 2. Comparison according to the location of cysts

\begin{tabular}{lccclcc}
\hline \multirow{2}{*}{ Location } & Sex (M:F) & Age (years) & Side (Rt.:Lt.) & Duration of symptom (min-max) & \multicolumn{2}{c}{ Size $(\mathrm{mm})$} \\
\cline { 6 - 8 } Helix & $1: 1$ & $21.4 \pm 12.4$ & $0: 2$ & Several years-several decades & $22.5 \pm 3.5$ & $11.5 \pm 4.9$ \\
Preauricular & $3: 1$ & $46.2 \pm 5.3$ & $1: 3$ & 3 months-3 years & $13.3 \pm 2.9$ & $9.7 \pm 2.6$ \\
Lobule & $3: 1$ & $40.9 \pm 16.9$ & $4: 0$ & 4 months-several years & $13.0 \pm 5.6$ & $10.0 \pm 4.3$ \\
Ear canal & $3: 1$ & $30.4 \pm 22.2$ & $1: 3$ & 4 days-several years & $9.3 \pm 3.3$ & $6.7 \pm 3.0$ \\
Postauricular & $1: 0$ & 54.6 & $1: 0$ & 1 year & 15.0 & 11.0 \\
\hline
\end{tabular}

Data were described using the mean \pm standard deviation. M: male, F: female, Rt.: right, Lt.: left and preauricular area $(p=0.021)$ but not in size $(p=0.168)$. The size of cysts of the ear canal was smaller than others, but there was no significant difference between it and others (Table 2).

\section{Discussion}

Epidermoid and dermoid cysts can be of congenital or acquired type. Most dermoid cysts are usually congenital but most epidermoid cysts of the skin are acquired. Both cysts of congenital type are due to failure of surface ectoderm to separate from underlying neural tube in cases of intracranial and spinal epidermoid and dermoid cysts but result from entrapment of ectodermal tissue between the midline fusion of first and second branchial arches in the head and neck regions. Entrapment of ectodermal tissue along the embryologic sites of dermal fusion make epidermoid and dermoid cyst in the head and neck regions. The cysts of acquired type usually occur due to infection around pilosebaceous follicle or sometimes deep implantation of epidermis as a result of penetrating or blunt injury, such as ear piecing [1-5].

Histologically, two cutaneous cysts differ in their internal structures in the lining of the wall. Common features of both are that both have keratinized and stratified squamous epithelium and eosinophilic, laminated keratin material within the thin wall. However, sebaceous glands, sweat glands and hair follicles are present only in dermoid but not in epidermoid. Epidermoid cyst consists of keratinous cyst covered by stratified squamous epithelium without adnexal structures but dermoid cyst contains keratin, sebaceous glands, hair follicles, and adnexal structures within the wall of stratified squamous epithelium.

Although iatrogenic dermoid cyst was reported in only a few reports, most dermoid cysts are usually congenital, especially in cases of intracranial ones. Contrary to dermoid cyst, the pathogenesis of epidermoid cyst is varied. Congenital type of epidermoid cysts may result from implantation of epidermal rest during embryonal period. Most entrapment of ectodermal tissue can occur along the embryologic sites of dermal fusion in the head and neck regions. Traumatic type can 
derive from traumatic or iatrogenic implementation of epidermal tissues and proliferation into the surrounding tissue. Most cases developing after ear piecing conform to this type. Idiopathic type may derive from blockage of hair cortex follicles and occlusion of a sebaceous gland after repeated infection of the pilosebaceous unit [1-5].

This study analyzed 15 cases of idiopathic epidermoid and dermoid cysts. Of 15 cases, 14 cases were epidermoid cysts. Only pediatric case was 5.2 years old girl, which was only case of dermoid cyst in this study. All epidermoid cysts found in adults (40.1 \pm 14.7 years old). This study did not show any site preference for occurrence; the location of epidermoid cysts was evenly distributed at the ear canal, at the preauricular area, at the lobule, and at the postauricular area.

The origin of the auricle is formed by 6 hillocks of first and second branchial arch. These 6 hillocks fuse each other and grow to form an auricle. During this developmental period, epidermoid and dermoid cyst can be developed. This study showed that most cutaneous cysts of the auricle are epidermoid cyst. Our finding is consistent with other articles, which found that dermoid cysts are generally seen in the midline. The most common location of dermoid cysts in the head-neck region is known to be around the eyes, followed by dorsum of the nose and midline of the neck [6,7].

The treatment of choice for epidermoid and dermoid cysts is complete excision. Our study suggests that surgeons should keep the tricky difference in removal of the cysts according to their location. Because this study did not find out any significant difference in age, sex, size and side according to the location, the difference in surgical technique might be based on the anatomical characteristic where the cyst was located. The preauricular cysts can be easily removed because its surgical procedure is the same as that of preauricular sinus and familiar with otologic surgeons. The cysts of helical auricle cartilage can be easily removed completely because underlying border of the cyst is cartilage and easily dissected without remnant cystic wall. In addition, its overlying skin can be easily preserved. The cysts of ear canal can be easily dissected and removed from underlying ear canal cartilage. However, it is difficult to preserve the skin overlying a cyst in cases of transcanal removal because of limited surgical exposure. If the loss of the skin overlying a cyst is small, the skin defect is healed spontaneously without any coverage of exposed ear canal cartilage. If the skin defect after the excision is large, circumferential or located deeply in the external auditory canal, the skin graft from postauricular skin area is enough for its coverage. For the cyst of ear lobule, complete excision seems to be easy but it is not easy for unexperienced surgeons to preserve the skin overlying a cyst. To preserve the skin and volume of an ear lobule, too diffident excision can make a part of the cystic wall be left, which results in recurrence. Too excessive excision often fails to preserve the skin overlying a cyst on both sides of ear lobule, through-andthrough surgical defect is developed. If the skin defect is small, primary closure is possible. If the skin defect is large, the skin graft is needed because primary closure makes postoperative constriction of an ear lobule.

In two cases, full-thickness skin graft was performed. The reason for full-thickness skin graft was not dependent on the characteristics of the cysts. Because 5.2 years old girl's small ear canal was filled by $13 \times 10 \mathrm{~cm}$-sized mass and about half ear canal skin overlying the cyst was removed together with it, full-thickness skin graft was done to prevent the postoperative stenosis of cartilaginous ear canal. The second case was a 32.8-year-old male, whose skin of the lateral ear lobule overlying the cyst was not dissected from the cyst. The skin surrounding the cyst on both sides of his ear lobule was removed together with the cyst and full-thickness skin graft was done to manage resultant through-and-through surgical defect.

In conclusion, this study showed that epidermoid cysts did not show any significant difference in age, sex, and size according to the location. This study also demonstrated that most cutaneous cysts around the ear were epidermoid cysts. In this study, there was no site preference for occurrence of epidermoid cysts.

\section{Conflicts of interest}

The authors have no financial conflicts of interest.

\section{REFERENCES}

1) Kim HK, Kim SM, Lee SH, Racadio JM, Shin MJ. Subcutaneous epidermal inclusion cysts: ultrasound (US) and MR imaging findings. Skeletal Radiol 2011;40:1415-9.

2) Park JS, Ko DK. A histopathologic study of epidermoid cysts in Korea: comparison between ruptured and unruptured epidermal cyst. Int J Clin Exp Pathol 2013;6:242-8.

3) Jung KH, Choi HJ, Nam DH. Characteristics of dermoid cyst of the auricle. Arch Craniofac Surg 2014;15:22-7.

4) Kim GW, Park JH, Kwon OJ, Kim DH, Kim CW. Clinical characteristics of epidermoid cysts of the external auditory canal. J Audiol Otol 2016;20:36-40.

5) Abdel-Aziz M. Epidermoid cyst of the external auditory canal in children: diagnosis and management. J Craniofac Surg 2011;22:1398-400.

6) Dabholkar JP, Patole AD, Sheth AS, Saaj R. Congenital cystic lesions in head and neck. Indian J Otolaryngol Head Neck Surg 2003;55:12830.

7) Görür K, Talas DU, Ozcan C. An unusual presentation of neck dermoid cyst. Eur Arch Otorhinolaryngol 2005;262:353-5. 